\title{
An Analysis of Social Vulnerability to Natural Hazards in Nepal Using a Modified Social Vulnerability Index
}

\author{
Sanam K. Aksha ${ }^{1} \cdot$ Luke Juran $^{1,2} \cdot$ Lynn M. Resler ${ }^{1} \cdot$ Yang Zhang $^{3}$
}

Published online: 16 November 2018

(C) The Author(s) 2018

\begin{abstract}
Social vulnerability influences the ability to prepare for, respond to, and recover from disasters. The identification of vulnerable populations and factors that contribute to their vulnerability are crucial for effective disaster risk reduction. Nepal exhibits multihazard risk and has experienced socioeconomic and political upheaval in recent decades, further increasing susceptibility to hazards. However, we still know little regarding social vulnerability in Nepal. Here, we investigate social vulnerability in Nepal by adapting Social Vulnerability Index (SoVI) methods to the Nepali context. Variables such as caste, and populations who cannot speak/understand Nepali were added to reflect the essence of the Nepali context. Using principal component analysis, 39 variables were reduced to seven factors that explained $63.02 \%$ of variance in the data. Factor scores were summarized to calculate final SoVI scores. The highest levels of social vulnerability are concentrated in the central and western Mountain, western Hill, and central and eastern Tarai regions of Nepal, while the least vulnerable areas are in the central and eastern Hill regions. These findings, supplemented with smaller-scale analyses, have the potential to assist village officers, policymakers, and emergency managers in the development of more effective and geographically targeted disaster management programs.
\end{abstract}

Sanam K. Aksha

sanam7@vt.edu

1 Department of Geography, Virginia Tech, Blacksburg, VA 24061, USA

2 Virginia Water Resources Research Center, Virginia Tech, Blacksburg, VA 24061, USA

3 Urban Affairs and Planning, Virginia Tech, Blacksburg, VA 24061, USA
Keywords Disaster risk reduction · Natural hazards · Nepal · Principal component analysis - Social Vulnerability Index

\section{Introduction}

The frequency and intensity of disasters are increasing globally (de Haen and Hemrich 2007; CRED 2015; Huggel et al. 2015). This escalation parallels increases in humanenvironment interaction and in the number of people and asset values exposed to hazards. Vulnerability measurement and assessment are recognized as key components for reducing losses from disasters and facilitating a culture of disaster resilience (Birkmann 2006b; Cutter and Finch 2008; Montz and Tobin 2011).

The concept of vulnerability has been applied in various fields, such as disaster studies, sustainable development, urban growth, gender studies, and climate change, to better understand susceptibility to stresses and shocks originating in environmental and social change. Interpretations of vulnerability depend on disciplinary perspective and context. Physical scientists, for example, tend to conceptualize vulnerability in terms of the likelihood of occurrence of a specific process and associated impacts on the built environment (Papathoma-Kohle et al. 2011; Fuchs et al. 2012). Social scientists tend to define vulnerability as a set of social, economic, and demographic factors that coalesce to determine people's ability to cope with stressors (Wisner et al. 2004; Juran and Trivedi 2015). In reality, the biophysical environment interacts with social attributes and systems to reveal vulnerability, meaning that vulnerability is socially constructed. Vulnerability ultimately manifests in stratification and unequal impacts among different 
groups of people across space. Consequently, vulnerability reduction requires knowledge of the factors that influence vulnerability coupled with a holistic understanding of the social, economic, and political contexts in which such factors operate (Hewitt 1997; Cutter et al. 2003; Wisner et al. 2004).

Much vulnerability research relies on qualitative assessments (Laska and Morrow 2006; Few and Pham 2010; Mallick et al. 2011), but there is growing interest in measuring vulnerability empirically (Armas 2008; Myers et al. 2008; de Oliveira Mendes 2009), especially social vulnerability. Among the most recognized methods is the Social Vulnerability Index (SoVI). Developed by Cutter et al. (2003), the SoVI framework uses place-based indicators in order to quantify and identify the biggest drivers of social vulnerability. The SoVI has undergone continuous evolution given deepening understandings of the nature and drivers of vulnerability (Cutter and Morath 2014), and it has been applied in various geographical and social contexts, such as Africa (Letsie and Grab 2015), Asia (Zhou et al. 2014), the Caribbean Islands (Boruff and Cutter 2007), Europe (Holand and Lujala 2013), and Latin America (Hummell et al. 2016).

Quantitative assessments of social vulnerability in Nepal are scarce due to the lack of availability of social data for analysis and mapping. Previous studies on vulnerability in Nepal have focused on either a specific physiographic region of the country (TU-CDES 2016) or a single hazard type, such as floods (Dixit 2003; Dixit et al. 2007; Devkota et al. 2013), landslides (Sudmeier-Rieux et al. 2012), earthquakes (Dixit et al. 2013; Dixit 2014), or severe weather events (Shrestha 2005). A recent study by Mainali and Pricope (2017) used a few socioeconomic variables in combination with high-resolution images to investigate vulnerability to climate change in Nepal. The study is valuable because it uncovers spatial variations of vulnerability across the country. However, it does not consider a wide range of social, economic, and demographic variables-for example, unemployment, or elderly, children, and minority populations - which would add much needed social dimensions of vulnerability to the study. The Ministry of Environment of the Government of Nepal (2010), in a district-level analysis of vulnerability to climate change, recommended a scale-dependent approach that focuses on the local level (villages and municipalities). The argument is that such analyses reveal finer-scale dynamics of vulnerability that may be concealed at larger scales. Thus, there exists a need for the quantification of social vulnerability across the entire country of Nepal at the local level.

To address this research gap, we developed and applied a modified SoVI to quantify social vulnerability to natural hazards in Nepal at the village and municipal level. The specific research questions are: (1) who are the most vulnerable populations in Nepal? and (2) where do they live? The objectives are to: (1) quantify social vulnerability at the village and municipal levels using indicators relevant to the Nepali context, and (2) assess the spatial dynamics of social vulnerability in the country. The SoVI is applied at the local level across the entire country and provides statistical and spatial findings that have the potential to improve disaster preparedness in Nepal.

\section{The Nepali Context}

Nepal is situated in the central Himalayan region surrounded by India on the east, west, and south, and by China in the north. The population of Nepal is about 26.5 million (CBS 2012) and is extremely diverse in exposure to hazards and with respect to numerous social, economic, and demographic attributes. These spatially differentiated factors must be considered in order to develop an appropriate SoVI.

\subsection{Socioeconomic Context}

The social, economic, and demographic attributes of Nepal, which intersect with geophysical and hydrometeorological processes, reflect directly on the social vulnerability of the country. The status of these attributes is rooted in a historically sluggish development process. In the past decades, development activities have been centered in the capital city of Kathmandu and a few other urban areas, marginalizing rural areas in the Mountain, Hill, and Tarai regions from the process. The socioeconomic situation is further aggravated by a lack of infrastructure, energy, government accountability, and financial resources. As a result, Nepal is struggling to escape the poverty trap and remains one of the least developed countries, ranking 144th in a recent Human Development Index (HDI) report (UNDP 2016). According to the latest census of 2011, the population has been growing steadily at more than $2 \%$ per annum and has close to tripled from the 1961 population of 9.5 million (CBS 2012). The total adult literacy rate is $59.6 \%$, with a female literacy rate of only $48.8 \%$. Nepal is predominantly an agrarian society with roughly $60 \%$ of the population dependent on subsistence agriculture. The majority of land is not arable due to the steep slopes and rocky soils of the mountainous region, and agriculture is highly monsoon-dependent. Poverty has compelled many to emigrate to neighboring countries and the Middle East in search of employment, which provides much needed remittances. The recent 2011 census reports that one in every four households $(25.4 \%)$ has at least one member living outside of Nepal, and the greatest proportion of the 
absentee population (44.8\%) is among the economically productive 15-24-year cohort (CBS 2012). Most migrants are male, and female-headed households have increased from $14.9 \%$ in 2001 to $25.7 \%$ in 2011 .

Nepal exhibits great demographic diversity, which influences social vulnerability. Hinduism is followed by more than $80 \%$ of the population (Buddhism and Islam are other common religions), but is comprised of many castes and subcastes. The 2011 census also accounts for 125 ethnic groups and 123 languages across this relatively small country (CBS 2012), and these demographics are geographically clustered. Only a few ethnic and caste groups are dispersed throughout the country-modern-day Nepal was formed in the 18th century by unifying numerous small principalities that were primarily based on caste, ethnicity, and language. Some of these social markers, specifically the caste system, lead to discrimination and social exclusion, especially in rural areas. Spatial attributes of these demographic features may be revealed through spatial analyses of social vulnerability scores.

Adding to the complicated socioeconomic and demographic contexts is the risk of and exposure to a multitude of hazards-such as earthquakes, floods, landslides, thunderstorms, debris flows, avalanches, glacial lake outburst floods (GLOFs), and forest fires-and these hazards are distributed unevenly throughout the country (Aksha et al. 2018). The 2015 Gorkha Earthquake alone killed about 9000 people and damaged or destroyed more than 750,000 buildings. A majority of the losses occurred in rural areas where low-quality, traditional masonry is the predominant housing material. Due to competition for resources such as jobs and land that is accessible, arable, and easy to develop, people are pushed into high-risk areas (Aryal 2014).

\subsection{Physical Context}

Nepal is situated in the Himalayas between India and China. Elevations range from just $57 \mathrm{~m}$ above sea level to Mt. Everest, at $8848 \mathrm{~m}$ the world's highest peak, within a relatively narrow latitudinal spread. Nepal is divided into three ecological regions: Tarai, Hill, and Mountain (Fig. 1). The Tarai region is the southernmost part of Nepal. This "grain basket" of the country has relatively low, flat, and fertile land comprised of alluvial soils. The Tarai region covers roughly $24 \%$ of the total area of Nepal, but is home to roughly $50 \%$ of the population. The Hill region rises from 1000 to $4000 \mathrm{~m}$ above sea level and comprises about $42 \%$ of Nepal's total area. The Hill region is the first orographic barrier to monsoon winds, which produce heavy precipitation on its southern flanks. The increasingly urbanized Kathmandu and Pokhara valleys lie in this region. North of the Hill region lies the Mountain region, which covers about $34 \%$ of the total land area of
Nepal. The Mountain region has subalpine to alpine climates and is characterized by river valleys, tectonic basins, snow-capped peaks, glaciers, rocky slopes, and colluvial deposits. This region is sparsely populated.

\subsection{Political Context}

Nepal was divided into five development regions, 14 zones, 75 districts, 53 municipalities, and 3918 village development committees (VDCs). However, in 2015, a new constitution was adopted that created three levels of governance: the federation, the province, and local bodies. Now, Nepal is divided into seven provinces and 744 local bodies (four metropolitan cities, 13 sub-metropolitan cities, 246 municipalities, and 481 rural municipalities), although administration through these bodies has not yet commenced. This study was based on the previous administrative bodies, that is, the 3918 VDCs and 53 municipalities. The previous bodies were chosen because the scale is smaller (total of 3971 spatial units compared to 744), which allows statistical and spatial analyses to produce finer results. The new administrative bodies were formed by simply combining groups of the previous bodies, so the new administrative bodies are still captured in our analyses, but at a finer scale. Use of the previous bodies supports analyses across more observations and more spatial units while still being administratively relevant. Finer-scale analyses are especially important in the Nepali context, which exhibits great socioeconomic, cultural, and physiographic diversity across short expanses of space.

\section{Materials and Methods}

In order to understand drivers of vulnerability at the village level in Nepal, we constructed a modified SoVI. We identified meaningful variables using the published literature. To reflect the socioeconomic, physical, and political context of the country, necessary adaptations were implemented as described in detail below.

\subsection{Data and SoVI Modification}

This study adopted the SoVI method developed by Cutter et al. (2003), which employed more than 200 variables to quantify and analyze social vulnerability in the United States. Conceptualizations of social vulnerability and the SoVI methodology have been refined over time and applied in many contexts (Boruff and Cutter 2007; Holand and Lujala 2013; Zhou et al. 2014; Hummell et al. 2016). Similarly, this study analyzed individual factors such as education, employment, ethnicity, and health as well as community characteristics such as level of urbanization, 


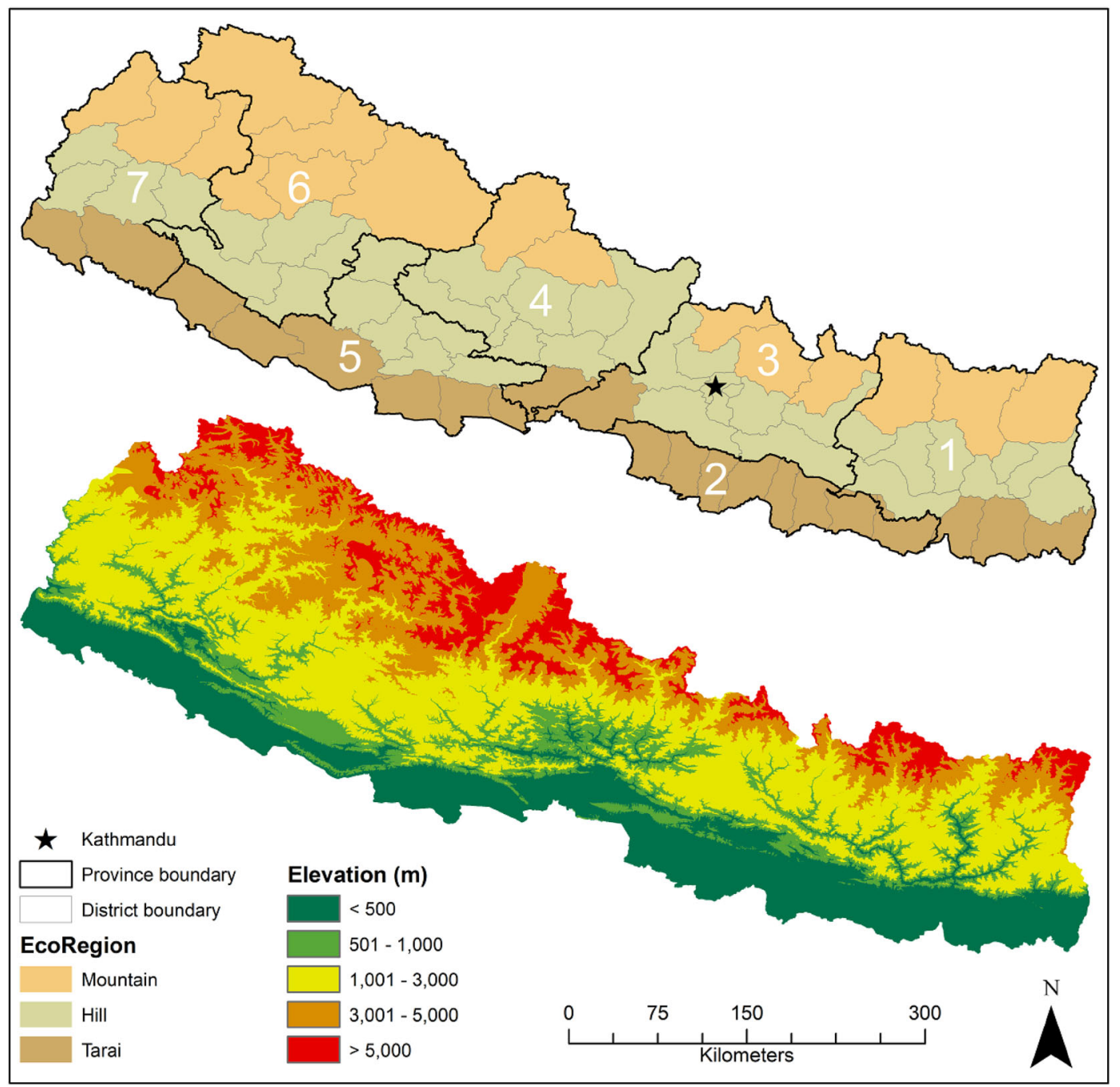

Fig. 1 Physical and administrative map of Nepal. The numbers 1-7, as indicated on the map, are the provinces created in 2015 that have yet to be named by the government

access to medical services, and built environment attributes to construct a modified SoVI for Nepal.

Since the original SoVI was applied to the United States context, modifications were necessary to adapt the model to Nepal's distinct sociophysical context. To construct the modified SoVI, we extracted data from the full dataset of the most recent 2011 census, which was provided by the Central Bureau of Statistics (CBS), Government of Nepal (CBS 2012). The CBS conducted the census using two household level questionnaires. The first questionnaire collected basic demographic data, and the second questionnaire included more detailed questions on topics such as migration, fertility, and economic activity. The CBS adopted a systematic sampling method, and roughly $15 \%$ of the entire population of Nepal were sampled. Using all available data from the 2011 census, Table 1 provides a list of concepts and variables used to construct the SoVI.
Modifications to the original SoVI were made to capture fundamental demographic differences between Nepal and the United States. To capture "Ethnicity" in Nepal we included Dalit (the lowest strata of the Hindu caste system) and Minority Populations. Dalits are considered "untouchable" and encounter systemic social and economic oppression. About $15.6 \%$ of the total population in Nepal are Dalits, and there are 26 distinct, concentrated Dalit groups distributed heterogeneously throughout Nepaleach with a different language, culture, religious practices, and means of employment (Dahal et al. 2002). Minority Populations encompasses indigenous populations and other historically disadvantaged groups. Indigenous populations in Nepal are defined as people who possess distinct cultural traditions, languages, and religious faiths based on animism (Bhattachan 2008). Fifty-nine separate groups are considered Minority Populations, and they are further divided into five categories based on their status: 
Table 1 Concepts and variables used to construct the modified Social Vulnerability Index for Nepal

\begin{tabular}{|c|c|c|c|}
\hline Concept & No. & Variable name & Description \\
\hline \multirow[t]{2}{*}{ Age } & 1 & PAGE65 & Percent elderly population $(65+$ years $)$ \\
\hline & 2 & PAGE5 & Percent children under 5 years \\
\hline \multirow[t]{5}{*}{ Built environment } & 3 & PNORCC & Percent households without reinforced cement concrete (RCC) foundation \\
\hline & 4 & PNOWATER & Percent households without piped water connection \\
\hline & 5 & PNOELECT & Percent households without electricity \\
\hline & 6 & PNOSEWER & Percent households without sewage infrastructure \\
\hline & 7 & PLOWALL & Percent population living in houses with low quality external walls \\
\hline \multirow[t]{3}{*}{ Education } & 8 & PILLIT & Percent population who cannot read and write \\
\hline & 9 & PSLC & Percent population who completed school leaving certificate (SLC) \\
\hline & 10 & PCOLLEGE & Percent population who completed college degree \\
\hline \multirow[t]{2}{*}{ Ethnicity } & 11 & PDALIT & Percent Dalit population \\
\hline & 12 & PMINOR & Percent minority population \\
\hline \multirow[t]{2}{*}{ Family structure } & 13 & PFEMHEAD & Percent female-headed households \\
\hline & 14 & AVGHH & Average number of people per household \\
\hline \multirow[t]{3}{*}{ Gender } & 15 & PFEM & Percent females \\
\hline & 16 & PFEMOWNH & Percent households that are female owned \\
\hline & 17 & PFEMOWNL & Percent households with land owned by female \\
\hline Level of employment & 18 & PUNEMPLOY & Percent unemployed \\
\hline \multirow[t]{2}{*}{ Medical services } & 19 & PBHEALTH & Number of basic health institutions per capita \\
\hline & 20 & PHEALTHPOP & Percent employed in health care and social services \\
\hline \multirow[t]{2}{*}{ Migration } & 21 & PFOREIGN & Percent non-Nepali (foreigners) population \\
\hline & 22 & PABSENTPOP & Percent absentee population \\
\hline \multirow[t]{6}{*}{ Occupation } & 23 & PAGRI & Percent employed in agriculture, forestry, fishing, mining, and quarrying \\
\hline & 24 & PMANU & Percent employed in manufacturing and construction \\
\hline & 25 & PTRANS & Percent employed in transportation, communication, and other public utilities \\
\hline & 26 & PACCOM & Percent employed in accommodation and food services \\
\hline & 27 & PPUBADM & Percent employed in public administration, defense, and social security \\
\hline & 28 & PTRADE & Percent employed in trade and commerce \\
\hline Population change & 29 & POPCHAN & Population change 2001-2011 \\
\hline Renters & 30 & PRENTER & Percent families occupying rented houses \\
\hline \multirow[t]{5}{*}{ Socioeconomic status } & 31 & PMORFAM & Percent families living in households with $>1$ family \\
\hline & 32 & PRADIO & Percent households with radio \\
\hline & 33 & PPHONE & Percent households with cell phone or landline \\
\hline & 34 & PVEHICLE & Percent households with automobiles \\
\hline & 35 & PNOCOM & Percent households without access to communication and transportation means \\
\hline \multirow[t]{2}{*}{ Special needs populations } & 36 & PDISABILITY & Percent population with disability \\
\hline & 37 & PNONEPALI & Percent population who does not speak/understand Nepali \\
\hline \multirow[t]{2}{*}{ Urban/rural } & 38 & PFUEL & Percent households that use firewood as fuel source \\
\hline & 39 & POPDEN & Population density \\
\hline
\end{tabular}

endangered, highly marginalized, marginalized, disadvantaged, and advanced. The advanced category, which consists of the Newar and Thakali castes, actually have the highest HDI values (Sharma et al. 2014) and were thus excluded from Minority Population status in our SoVI. However, Muslims and Sikhs/Punjabis were included since they are considered disadvantaged groups who together account for less than $5 \%$ of Nepal's total population.

We also included "Built Environment" variables to reflect physical attributes of housing and public services such as electricity, water, and sewer infrastructures, as similarly included in a SoVI in Brazil by Hummell et al. (2016). According to the 2011 census, $25 \%$ of houses have 
external walls constructed from low-quality materials such as bamboo and wood, and only $10 \%$ of houses have reinforced cement concrete (RCC) foundations. As the entirety of Nepal lies in a highly active seismic belt, housing foundations and wall materials significantly impact vulnerability. Many fatalities from the 2015 Gorkha Earthquake, for example, were among people residing in lowquality houses. Severe damages were sustained by traditional mud and stone houses, especially in rural areas. In addition to housing quality, only $52 \%$ of households are connected to a piped water supply, only $39 \%$ have a toilet or latrine, and $33 \%$ are without electricity as their primary source of energy.

Populations who do not speak/understand Nepali were added to the "Special Needs Populations" indicator because inability to speak or understand Nepali substantially restricts access to critical and timely knowledge on disaster warnings as well as post-disaster recovery and rehabilitation programs. In the census questionnaire, individuals were asked to report their mother tongue and second language. Those who did not report Nepali were identified as individuals who do not speak/understand the Nepali language. Knowing the most widely spoken language is important because it is used extensively for basic communication and relaying information on disasters. Such populations also encounter linguistic issues (for example, completing and submitting official forms) when attempting to receive compensation and other support from the government. Although Nepali is no longer the official national language, it is the only language used for administrative and government communications, which constitutes a major disadvantage for nonspeakers, especially in emergency situations.

\subsection{Methods}

A total of 39 variables were selected for the construction of the modified SoVI (see Table 1). All variables were normalized using percentage, density, or per capita functions prior to statistical analysis. Principal component analysis (PCA) via Statistical Package for the Social Sciences (SPSS) version 21.0 software generated a set of independent factors. Principal component analysis is a factor reduction methodology that identifies a smaller number of components to explain the variance observed in a larger dataset (Abdi and Williams 2010). The purpose of performing PCA is to distill a broad explanation of the data by grouping like-variables into components that adequately account for covariation among the larger number of analysis variables. The analysis also facilitates the interpretation of component groups and provides insight when data are examined with further analyses. Following methods developed by Cutter et al. (2003), Kaiser normalization and
Varimax rotation were employed as extraction methods for components. Only components with eigenvalues higher than 1.0 were extracted and named to indicate the latent variables. Each component was named and assigned cardinality $( \pm)$. The SoVI was calculated by adding the scores of each component to arrive at total SoVI scores. An equal weighting and additive approach was used in the absence of empirical and justifiable evidence for weighting components differently, as has been exercised in similar studies (Cutter et al. 2003; Hummell et al. 2016). Our modified SoVI for Nepal was calculated for each spatial unit (the 3918 village development committees and 53 municipalities) by adding the principal component values:

SoVI $_{\text {village }}=\mathrm{PC} 1+\mathrm{PC} 2-\mathrm{PC} 3+\mathrm{PC} 4+\mathrm{PC} 5+\mathrm{PC} 6-\mathrm{PC} 7$

The SoVI scores of each spatial unit were mapped using ArcMap version 10.3 to visualize the most and the least vulnerable villages in Nepal based on standard deviation from the mean value. We used global and local Moran's $I$ tests of spatial autocorrelation to investigate whether social vulnerability is clustered or random across space in statistical terms. Global and local tests calculate autocorrelation among all villages and determine statistically significant patterns of similarity and dissimilarity in the spatial location and distribution of social vulnerability. The global Moran's $I$ test determines whether the geolocations of index results exhibit a spatial pattern. The interpretation is similar to that of correlation coefficients: values close to +1 indicate strong positive spatial autocorrelation (that is, clustering of either high or low values of social vulnerability), while values close to -1 indicate strong negative spatial autocorrelation (that is, alternation of high and low values for adjacent observations). Values near zero indicate the absence of spatial patterns, or randomness.

Local Moran's I was deployed to classify identified clusters according to type of association. These results were used to map four typological gradations of social vulnerability at the village and municipal level: (1) HighHigh $(\mathrm{HH})$, a village with a high SoVI score surrounded by villages with high SoVI scores; (2) Low-Low (LL), a village with a low SoVI score surrounded by villages with low SoVI scores; (3) High-Low (HL), a village with a high SoVI score surrounded by villages with low SoVI scores; and (4) Low-High (LH), a village with a low SoVI score surrounded by villages with high SoVI scores. Hot spots (HH) and cold spots (LL) denote positive spatial autocorrelation, indicating clusters of similar values, whereas $\mathrm{LH}$ and HL denote negative spatial autocorrelation, indicating clusters of dissimilar values. Together, global and local spatial analyses identify patterns of social vulnerability that are either not visible (that is, masked) or appear visually meaningful yet are not statistically significant (that is, false 
positives). The inclusion of spatial clustering advances the original research work using the SoVI method by Cutter et al. (2003) by adding new analytical abilities to the method.

\section{Results}

The PCA uncovered seven components with eigenvalues greater than 1.0. Based on loaded variables and their cardinality, the seven components were named Renters and Occupation, Poverty and Poor Infrastructure, Favorable Social Conditions, Migration and Gender, Ethnicity, Medical Services, and Education. In total, the principal components explain $63.02 \%$ of the variance of the data. Descriptions of the seven components, signs denoting their effect on social vulnerability, and loadings are presented in Table 2 .

Total SoVI scores were calculated by summing all seven principal components based on their cardinality, and the mean and standard deviations (SD) of the scores were also calculated. Based on SD values, vulnerability scores were grouped into five quintiles from most $(>1.5 \mathrm{SD})$ to least $(<-1.5 \mathrm{SD})$ vulnerable. Using ArcMap, we subsequently mapped total SoVI scores (Fig. 2) and the value of each component to visualize social vulnerability across Nepal (Fig. 3). Total SoVI scores (Fig. 2) reveal that the most socially vulnerable villages are located in the eastern and central Tarai region; the western Hill region; and the central and western Mountain regions. The least vulnerable villages are located in the eastern and central Hill regions. The capital city of Kathmandu is also highly vulnerable. In terms of districts, the Hill and Mountain districts of Provinces 6 and 7, and the Tarai districts of Provinces 1 and 2 contain a predominant number of villages and municipalities with high social vulnerability. The eastern Hill districts of Province 1 contain a majority of the villages and municipalities with low SoVI scores.

The geographic distribution of the principal component values is displayed in Fig. 3. Highly vulnerable areas for the Renters and Occupation component are concentrated in urban centers, particularly in Kathmandu and the Mountain region. Vulnerability for Poverty and Poor Infrastructure is concentrated in the Tarai region. For example, almost every village and municipality in the Tarai districts of Provinces 1, 2, and 5 exhibit high vulnerability in terms of Poverty and Poor Infrastructure. The third component, Favorable Social Conditions, exhibits greater levels of vulnerability across the entire Tarai region as well as pockets of the eastern and central Hill region. Relatively vulnerable areas for Migration and Gender, the fourth component, are distributed across the entire Tarai and Hill regions with a distinct concentration in the geographic center of Nepal. The highest levels of social vulnerability for component five, Ethnicity, are located in the western part of all regions of Nepal, as well as the eastern Tarai region. The Medical Services component reveals relatively high vulnerability in the Mountain region, with vulnerability decreasing with decreasing elevation. The final component, Education, reveals higher vulnerability in central and eastern Nepal-especially the eastern Tarai region-with pockets of the western Mountain region also revealing high levels of social vulnerability.

To test for clustering, we calculated global Moran's I statistics of SoVI scores in an ArcMap environment. We used the polygon contiguity concept to specify spatial relationships among villages and municipalities, which defines neighboring villages as those that share a boundary (Scott and Janikas 2010). The global Moran's I test confirmed positive spatial autocorrelation with a value of 0.41 $(p<0.001)$ and a z-score of 44.13. We employed a local's Moran's $I$ test to decompose global statistics into local clusters and identify pockets of association in terms of high and low values (Fig. 4). The results indicate that $\mathrm{HH}$ clusters are present in the western Hill and Mountain regions, although there are smaller, isolated pockets in the eastern Tarai region. Clusters of LL values were detected in the eastern and central parts of the Hill and Mountain regions.

\section{Discussion}

The objective of this study was to quantify social vulnerability at the local level using indicators relevant to Nepal's distinct social and physical landscapes. Following Cutter et al.'s (2003) SoVI methodology, we derived seven components that contribute to social vulnerability in Nepal (see Table 2). Component and total SoVI scores are not evenly distributed across the country, and clustering is evident (Fig. 4).

A major finding of this study is that areas with similar hydrometeorological and geophysical characteristics may exhibit differences in social vulnerability. Marked differences are observed in the spatial distribution of social vulnerability among the three ecological regions. The central and western Mountain, western Hill, and central and eastern Tarai regions exhibit relatively higher social vulnerability, while the central and eastern Hill regions reveal comparatively less vulnerability. This finding is interesting because elevation, natural hazard risk, and geophysical and hydrometeorological regimes are similar within each ecological region, but social vulnerability is not. Thus, while populations residing within each region are subjected to similar natural environments (and thus exhibit similar exposure to the same natural hazards), our 
Table 2 Principal components (PC), cardinality, variables, loadings, and explained variance for the modified Social Vulnerability Index in Nepal

\begin{tabular}{|c|c|c|c|c|}
\hline Component name & Cardinality & Variables & Loadings & Explained variance $(\%)$ \\
\hline \multirow[t]{12}{*}{ 1. Renters and Occupation (PC1) } & \multirow[t]{12}{*}{$(+)$} & PRENTER & 0.824 & \multirow[t]{12}{*}{15.97} \\
\hline & & PTRADE & 0.773 & \\
\hline & & PAGRI & -0.764 & \\
\hline & & PTRANS & 0.674 & \\
\hline & & PPUBADM & 0.647 & \\
\hline & & PMANU & 0.6 & \\
\hline & & PACCOM & 0.537 & \\
\hline & & PCOLLEGE & 0.681 & \\
\hline & & PSLC & 0.594 & \\
\hline & & PHEALTHPOP & 0.589 & \\
\hline & & PNORCC & -0.739 & \\
\hline & & POPDEN & 0.407 & \\
\hline \multirow[t]{11}{*}{ 2. Poverty and Poor Infrastructure (PC2) } & \multirow[t]{11}{*}{$(+)$} & PNOWATER & 0.824 & \multirow[t]{11}{*}{14.65} \\
\hline & & PNOSEWER & 0.675 & \\
\hline & & PLOWALL & 0.778 & \\
\hline & & PVEHICLE & 0.806 & \\
\hline & & PRADIO & -0.738 & \\
\hline & & PMOREFAM & 0.428 & \\
\hline & & PFUEL & -0.656 & \\
\hline & & PILLIT & 0.648 & \\
\hline & & PNONEPALI & 0.588 & \\
\hline & & AVGHH & 0.519 & \\
\hline & & PFOREIGN & 0.406 & \\
\hline \multirow[t]{8}{*}{ 3. Favorable social conditions (PC3) } & \multirow[t]{8}{*}{$(-)$} & PFEMOWNL & 0.762 & \multirow[t]{8}{*}{12.36} \\
\hline & & PFEMOWNH & 0.703 & \\
\hline & & PNOCOM & -0.781 & \\
\hline & & PPHONE & 0.748 & \\
\hline & & PAGE5 & -0.685 & \\
\hline & & PNOELECT & -0.684 & \\
\hline & & PSLC & 0.444 & \\
\hline & & PILLIT & -0.42 & \\
\hline \multirow[t]{4}{*}{ 4. Migration and gender (PC4) } & \multirow[t]{4}{*}{$(+)$} & PABSENTPOP & 0.833 & \multirow[t]{4}{*}{7.03} \\
\hline & & PFEM & 0.732 & \\
\hline & & PFEMHEAD & 0.791 & \\
\hline & & AVGHH & -0.452 & \\
\hline \multirow[t]{3}{*}{ 5. Ethnicity (PC5) } & \multirow[t]{3}{*}{$(+)$} & PDALIT & 0.727 & \multirow[t]{3}{*}{4.86} \\
\hline & & PMINOR & -0.819 & \\
\hline & & PMORFAM & 0.521 & \\
\hline \multirow[t]{3}{*}{ 6. Medical services (PC6) } & \multirow[t]{3}{*}{$(+)$} & PBHEALTH & 0.789 & \multirow[t]{3}{*}{4.68} \\
\hline & & PAGE65 & 0.476 & \\
\hline & & PACCOM & 0.401 & \\
\hline \multirow[t]{2}{*}{ 7. Education (PC7) } & \multirow[t]{2}{*}{$(-)$} & PCOLLEGE & 0.445 & \multirow[t]{2}{*}{3.47} \\
\hline & & PSLC & 0.431 & \\
\hline
\end{tabular}

findings suggest that social, economic, and built environment attributes make the places different in terms of level of social vulnerability, which in turn affects the levels of disaster risks. A majority of villages and municipalities in the central and eastern Tarai regions, which contain a disproportionate amount of the population, are categorized 


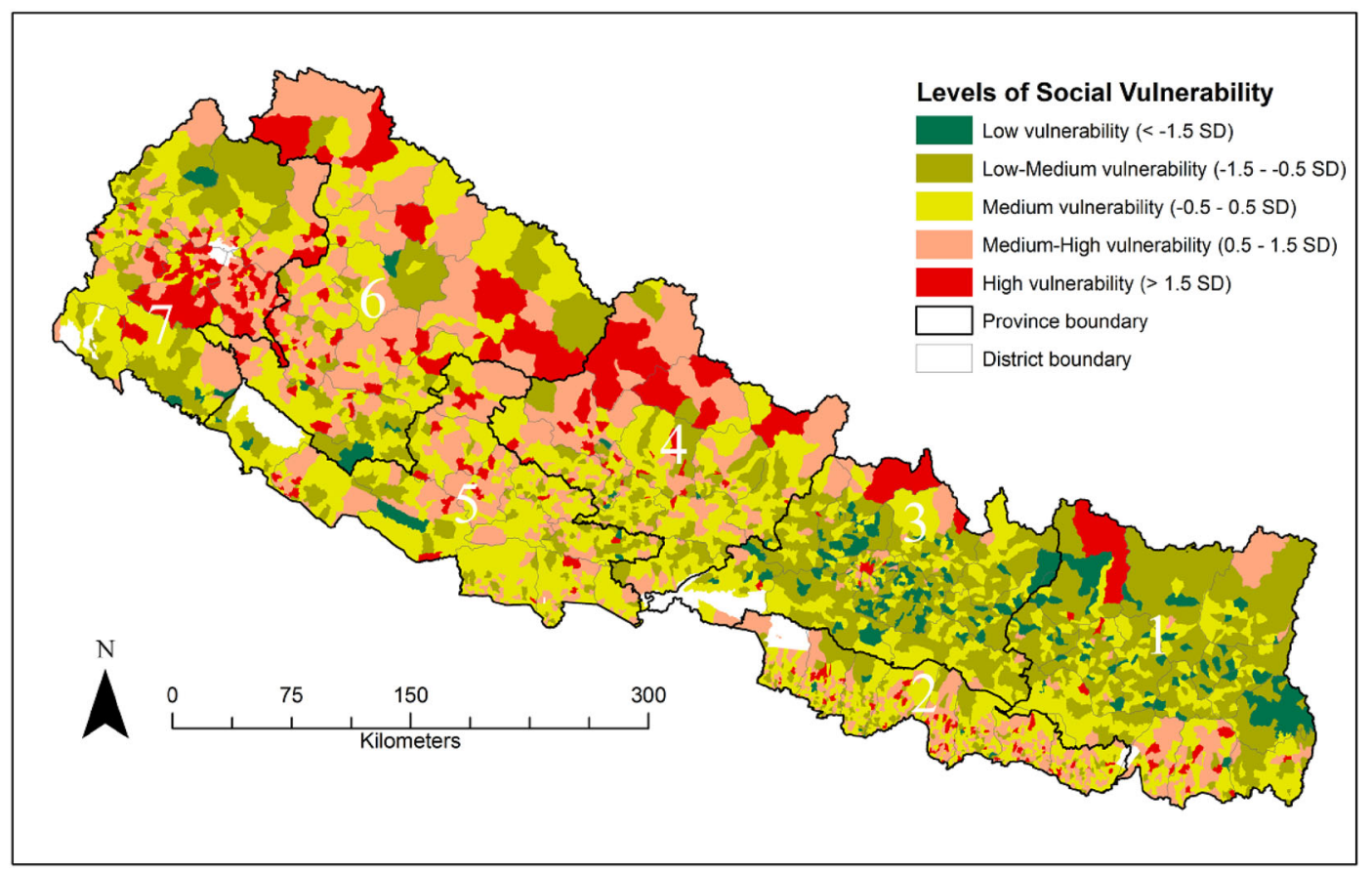

Fig. 2 Spatial distribution of the composite score of social vulnerability using a modified Social Vulnerability Index in the seven provinces of Nepal. The numbers 1-7, as indicated on the map, are the provinces created in 2015 that have yet to be named by the government

in the High and Medium-High vulnerability classes, whereas population centers in the western Tarai region are primarily classified as Medium or lower. These results parallel the fact that the central and eastern Tarai regions lag behind in education and health while also being home to a large number of poor, Dalit, and minority groups (Sharma et al. 2014). As for the Hill and Mountain regions, the 1996-2006 armed political conflict emerged in the western Hill region and then expanded. Due to geographic proximity, villages and municipalities in the western Hill and central and western Mountain regions were acutely affected, further paralyzing the development trajectory of already isolated segments of the country.

Our regional findings both correspond and contrast with previous studies. For example, while Mainali and Pricope's (2017) investigation of climate change vulnerability similarly contends that western portions of the Hill and Mountain regions exhibit relatively greater vulnerability, they classify the central and eastern Tarai regions in a low to moderate category. This classification contrasts with our identification of the central and eastern Tarai regions as relatively highly vulnerable. Our results also indicate that villages and municipalities in the central and eastern Hill regions are relatively less vulnerable, but the Ministry of Environment of the Government of Nepal (2010), in a report on climate change and climate-related disasters, claims that these areas are highly vulnerable. A study by K.C. (2013), which investigated flood and landslide vulnerability between Tarai and non-Tarai districts through the lens of education, found that vulnerability is greater in the Tarai region compared to the remainder of the country. However, our analyses reveal that the western Tarai region performs relatively well in educational attainment and is less vulnerable than the rest of the Tarai region and many other parts of the country. Observed collectively, discrepancies with similar studies are likely linked to (1) the spatial units of analysis; and (2) the type(s) of haz$\operatorname{ard}(\mathrm{s})$ considered. The studies by K.C. (2013) and the Ministry of Environment of the Government of Nepal (2010) used districts as the spatial unit of analysis, but our study used smaller-scale villages and municipalities. Additionally, our study considered multiple hazard types (rather than only floods, landslides, and/or climate-related hazards) and used more variables. We argue that smallerscale analyses and consideration of more variables has potential to generate more refined and spatially explicit results. Further, we argue that incorporating multiple hazards (as opposed to a single hazard type) is more realistic in a complex, dynamic, and compounding sociophysical environment such as Nepal.

Social vulnerability is discussed above at the composite SoVI and regional scales; however, drivers of vulnerability vary at the component and local scales. The Medical Services component, for example, exhibits a distinct geographic pattern: Mountain villages are highly vulnerable, with vulnerability decreasing as elevation decreases. Mountain villages are sparsely populated and are characterized by remoteness and isolation, which results in poor 
Renters \& Occupation

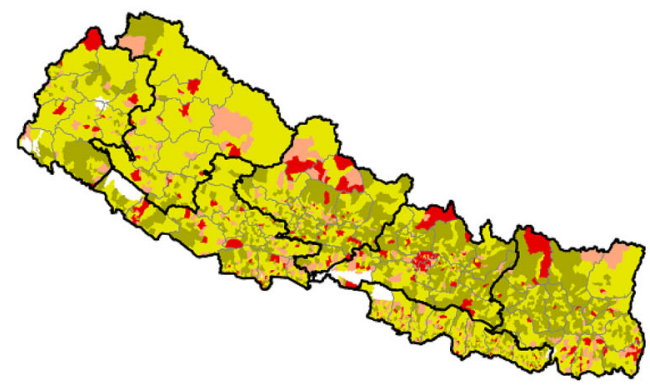

Favorable Social Conditions

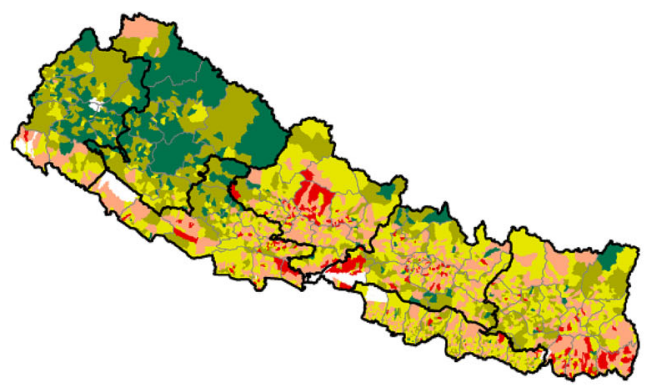

Ethnicity

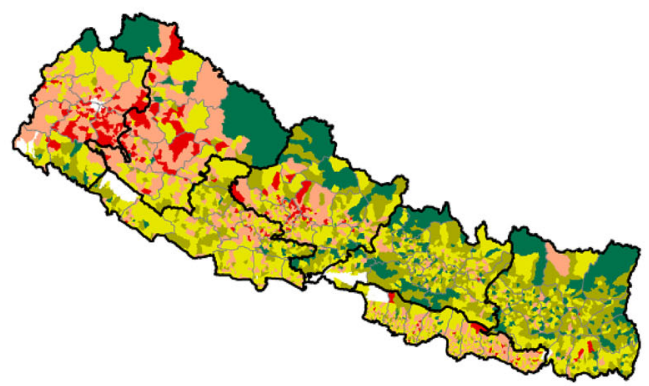

Education

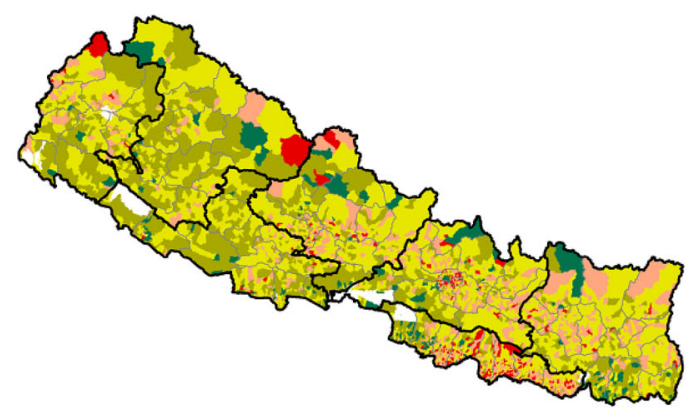

Poverty \& Poor Infrastructure

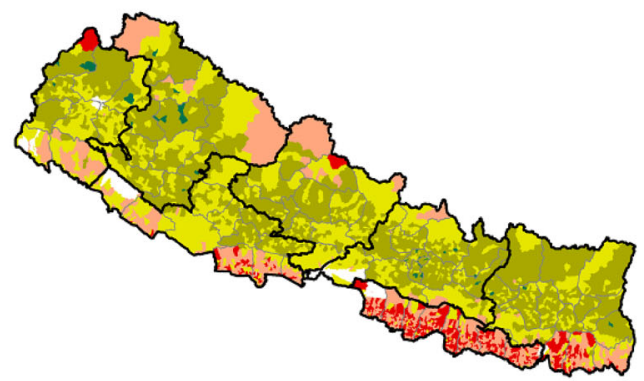

Migration \& Gender

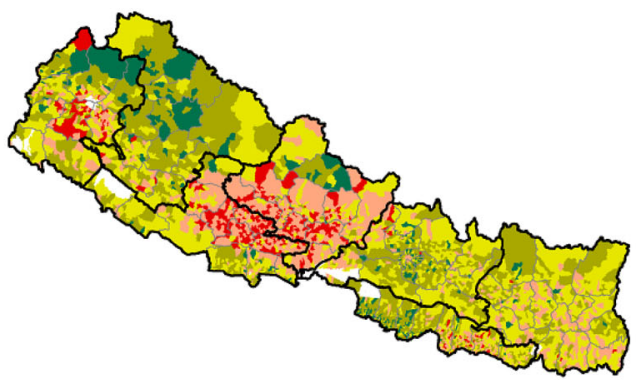

Medical Services

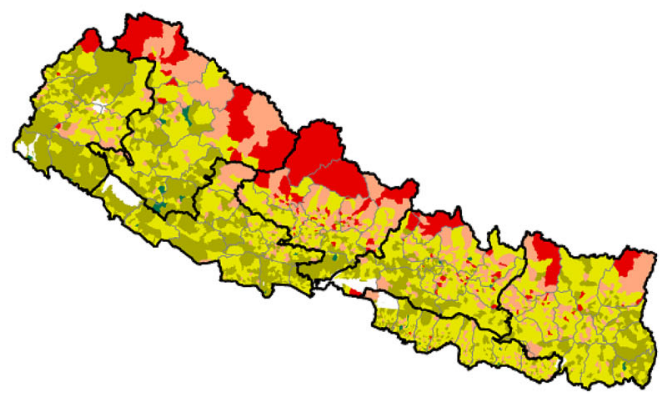

Levels of Social Vulnerability - Components

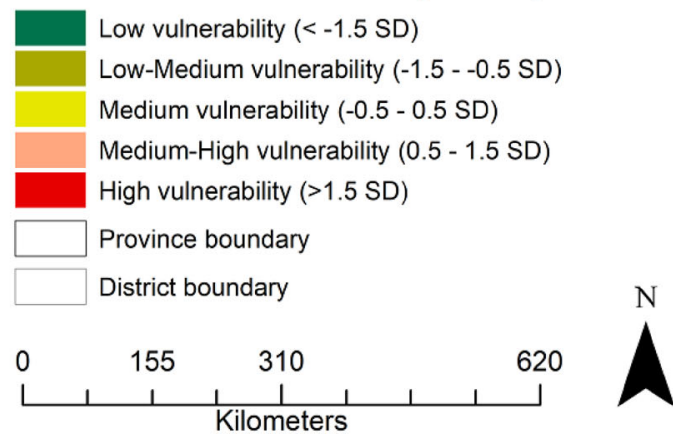

Fig. 3 Geographic distribution of principal component values of the modified Social Vulnerability Index in the seven provinces of Nepal 
Fig. 4 Spatial clustering of social vulnerability in Nepal based on a local Moran's I test

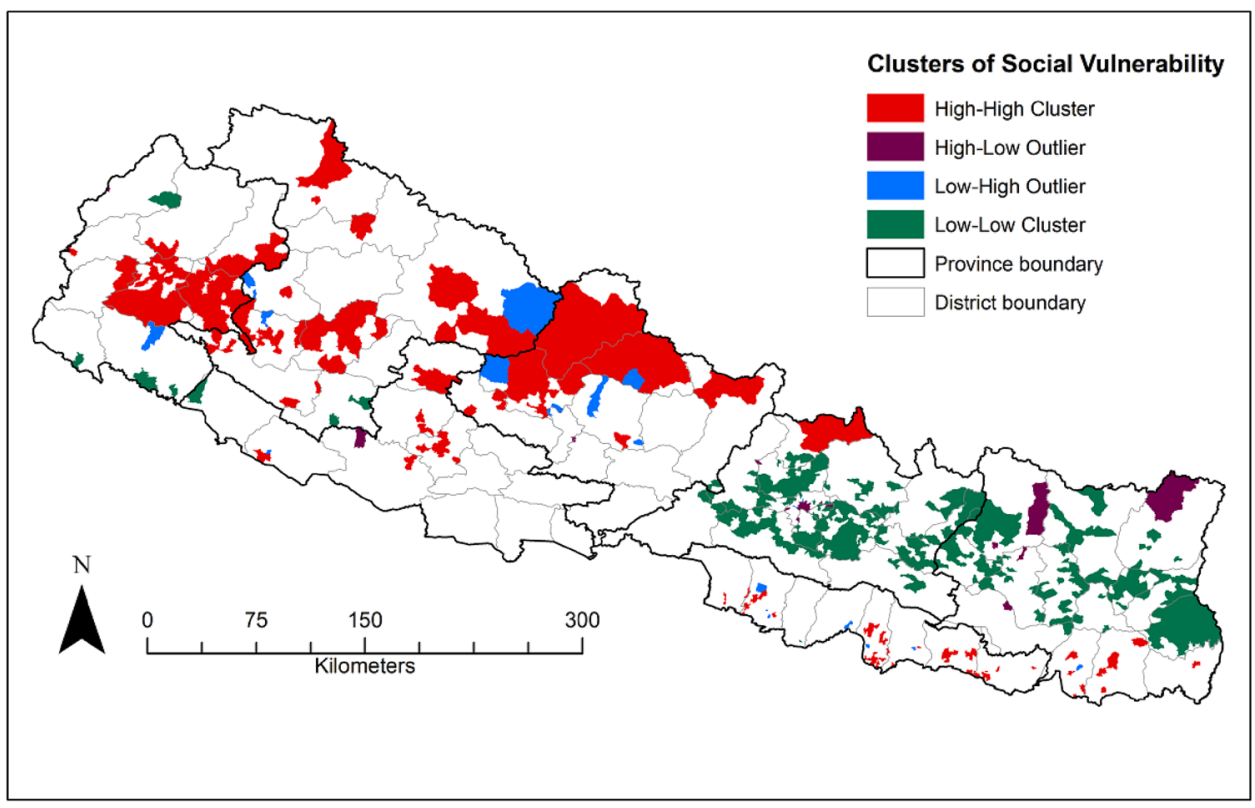

access to health facilities. As elevation decreases, population size and concentration increase and thus result in greater numbers of health facilities. We also overlaid the new province boundaries (see Fig. 1) and found that a majority of villages in Provinces 2, 4, 6, and 7 are classified in the High vulnerability category, whereas a majority of villages in Provinces 1 and 3 are classified as Low.

At the district level, the spatial distribution of social vulnerability reflects historical development patterns of the country. In terms of HDI values, the ten lowest districtswhich are predominantly in the western Hill and western Mountain regions. These districts are also identified as highly vulnerable in our study, with a majority of villages and municipalities from the districts classified in the High and Medium-High vulnerability classes. Historically, districts in western Nepal are relatively poorer, exhibit lower literacy rates, lack infrastructure (for example, transportation and hospitals), and have been alienated from mainstream development projects, although they have received greater allotments of development aid in recent years. Western districts were substantially impacted by the 1996-2006 armed conflict. Due to geographic isolation, push factors, and the vicious cycle of poverty, these districts have a dependence on natural resources, such as forests, and high rates of migration to the Middle East as laborers.

Major cities of Nepal fall into different vulnerability categories. Table 3 provides an overview of the 10 most populous cities and their vulnerability classes. Kathmandu and Butwal are identified as the most vulnerable cities, and Biratnagar and Dharan are classified as Medium-High. None of Nepal's major urban centers are classified as Low vulnerability. Among urban centers, major drivers of social vulnerability are Renters and Occupation and/or Poverty and Poor Infrastructure. According to the 2011 census, the average annual population growth rate of Nepal was $1.35 \%$ from 2001 to 2011, but all major cities exceeded this rateparticularly the two most vulnerable cities of Kathmandu and Butwal. Urban centers have experienced significant rural-to-urban migration in recent years, thus exposing increasing numbers of people to natural hazard risk. Furthermore, infrastructure, public services, and utilities are already serving more users than they can accommodate. In our study, Kathmandu was identified as the most vulnerable city in Nepal, but similar studies disagree. K.C. (2013), for example, found that educational attainment is highest in Kathmandu and thus the city is relatively less vulnerable compared to other cities, while Mainali and Pricope (2017) found that Kathmandu is less vulnerable to climate-related disasters compared to the rest of the country. The authors suggest that this could be explained by greater access to resources compared to other parts of the country. We argue that our analysis of smaller spatial units, inclusion of more variables, and consideration of multiple hazards helps to explain differences in the respective research findings.

Only 206 of close to 4000 villages and municipalities (roughly 5\%) are classified in the Low vulnerability class. Even more striking, this categorization of Low is solely in relation to other jurisdictions in Nepal, meaning that it does not consider the larger international context. The entirety of Nepal is located in a high-risk zone for natural hazards. Thus, a classification of Low in our study-which only considers Nepal-may actually be quite vulnerable compared to places that are classified as low in other countries. A measure of low vulnerability in a country that is less hazard-prone and socially, economically, and politically 
Table 3 Level of social vulnerability of Nepal's 10 largest cities

\begin{tabular}{llllcc}
\hline & Municipality & Population (2011) & Population growth rate (2001-2011) & SoVI score & Vulnerability class \\
\hline 1 & Kathmandu Metropolitan & $1,003,285$ & 4.01 & 6.1742 & High \\
2 & Pokhara Sub-Metropolitan & 264,991 & 5.28 & -0.9379 & Medium \\
3 & Lalitpur Sub-Metropolitan & 226,728 & 3.30 & 0.9253 & Medium \\
4 & Biratnagar Sub-Metropolitan & 204,949 & 2.07 & 3.4703 & Medium-High \\
5 & Bharatpur Municipality & 147,777 & 5.03 & -0.5845 & Medium \\
6 & Birgunj Sub-Metropolitan & 139,068 & 2.12 & -0.7854 & Medium \\
7 & Butwal Municipality & 120,982 & 4.73 & 4.9134 & High \\
8 & Dharan Municipality & 119,915 & 2.29 & 1.7084 & Medium-High \\
9 & Bhimdatta Municipality & 106,666 & 2.77 & -1.2839 & Low-Medium \\
10 & Dhangadhi Municipality & 104,047 & 4.34 & -2.7208 & Low-Medium \\
\hline
\end{tabular}

well off does not mean the same as low vulnerability in Nepal.

Nepal is extremely vulnerable to climate change given its hydrometeorological and physiographic extremes, which expose the country to flash and riverine floods; landslides, mudslides, and debris flows; and GLOFs (Shrestha and Aryal 2011; Immerzeel et al. 2012). In terms of social vulnerability, these risks are compounded by a reliance on agriculture, natural resource extraction, and primary sector economic activities-all of which impact Nepal's already fragile landscape. The fifth assessment report of the Intergovernmental Panel on Climate Change not only projects a higher warming trend for South Asia compared to the global mean (Christensen et al. 2014), but warming is expected to be more pronounced in high-altitude regions compared to lowlands (Shrestha et al. 1999; Aryal et al. 2014). This study has identified the high-altitude Mountain villages and municipalities of Nepal as highly vulnerable, and predictions of global warming threaten to exacerbate this vulnerability with greater risk of floods, landslides, GLOFs, and other hazards (Bajracharya and Mool 2009; Shrestha and Aryal 2011). Further adding relevance to social vulnerability, disaster mitigation programs and policies in Nepal have historically been reactive, focusing on structural solutions on an event-by-event basis (Dixit 2003). This approach fails to address many underlying factors of social vulnerability, including education, poverty alleviation, and communication of disaster information via several languages and media. This study provides a comprehensive assessment of social vulnerability at the local level, and could assist policymakers in proactively deploying programs and policies to reduce disaster risk.

Lack of data availability is typically the most limiting factor in measuring social vulnerability to natural hazards. This can lead to a reliance on easily measurable variables and result in the misrepresentation (for example, concealment or masking) of people and the complex physical and political-economic contexts in which they reside
(Birkmann 2006a; Zhou et al. 2014; Burton 2015). This study used complete, long-form data from the most recent 2011 census of Nepal, which sampled roughly $15 \%$ of the population (CBS 2012). Based on our knowledge, this represents the largest, most comprehensive, and geographically most extensive dataset for the country. However, one critique is that this study was unable to explicitly include data on income, which may have influenced our measurements of social vulnerability. The CBS utilizes a living standard survey that measures consumption as a surrogate for income. We supplemented these data with several related measurements of employment, occupation, educational attainment, literacy, and vehicle ownership. As another critique, other factors that are generally considered to shape social vulnerability-such as access to resources (including information and political power), age of infrastructure, and risk perception and awareness-could not be included in this study. Future analyses of social vulnerability in Nepal should attempt to overcome these shortcomings.

\section{Conclusion}

Based on the underlying socioeconomic and demographic profiles of close to 4000 villages and municipalities, this study investigated spatial patterns of social vulnerability in Nepal using an adapted SoVI methodology. In terms of ecological regions, the western Hill, central and western Mountain, and central and eastern Tarai regions were determined the most vulnerable. The central and eastern Hill regions were determined the least vulnerable. Demographics and historical development processes are essentially reflected in the geographic distribution of social vulnerability. That is, social vulnerability is particularly high in areas that have concentrations of Dalit and minority populations and/or a history of armed conflict, with mountain communities (which have poor access to 
infrastructure and critical services) overrepresented. As far as we are aware, this analysis is the first attempt to quantify social vulnerability at the local level across the entire country of Nepal.

Nepal is attempting to make progress in disaster risk reduction. Unfortunately, the 2015 Gorkha Earthquake set the country back and added additional urgency to the daunting task of making communities more resilient. This recent earthquake brought much needed attention to social components of vulnerability that have primarily remained unaddressed in favor of structural mitigation. This shift is important, and our study can help to provide a sciencebased starting point. Because this study is based on census data (which occurs in intervals of 10 years), it can be periodically revised to monitor changes over time and measure the impacts of disaster programs and policies. This study provides a visual understanding of the geographic distribution of social vulnerability in Nepal, which may inform policy making, resource allocation, and disaster management among government officials and nongovernmental organizations at the local level.

Open Access This article is distributed under the terms of the Creative Commons Attribution 4.0 International License (http://crea tivecommons.org/licenses/by/4.0/), which permits unrestricted use, distribution, and reproduction in any medium, provided you give appropriate credit to the original author(s) and the source, provide a link to the Creative Commons license, and indicate if changes were made.

\section{References}

Abdi, H., and L.J. Williams. 2010. Principal component analysis. Wiley Interdisciplinary Reviews: Computational Statistics 2(4): 433-459.

Aksha, S.K., L. Juran, and L.M. Resler. 2018. Spatial and temporal analysis of natural hazard mortality in Nepal. Environmental Hazards 17(2): 163-179.

Armas, I. 2008. Social vulnerability and seismic risk perception. Case study: The historic center of the Bucharest Municipality/ Romania. Natural Hazards 47(3): 397-410.

Aryal, K.R. 2014. Disaster vulnerability in Nepal. International Journal of Disaster Risk Reduction 9: 137-146.

Aryal, S., G. Cockfield, and T.N. Maraseni. 2014. Vulnerability of Himalayan transhumant communities to climate change. $\mathrm{Cli}$ matic Change 125(2): 193-208.

Bajracharya, S.R., and P.K. Mool. 2009. Glaciers, glacial lakes and glacial lake outburst floods in the Mount Everest region, Nepal. Annals of Glaciology 50(53): 81-86.

Bhattachan, K.B. 2008. Indigenous peoples \& minorities of Nepal. http://www.nefin.org.np/articles/dr-krishna-b-bhattachan/377indigenouspeoples-a-minorities-of-nepal. Accessed 16 Jun 2017.

Birkmann, J. 2006a. Indicators and criteria for measuring vulnerability: Theoretical bases and requirements. In Measuring vulnerability to natural hazards: Towards disaster resilient societies, ed. J. Birkmann, 55-77. Tokyo: United Nations University Press.

Birkmann, J. 2006b. Measuring vulnerability to promote disasterresilient societies: Conceptual frameworks and definitions. In Measuring vulnerability to natural hazards: Towards disaster resilient societies, ed. J. Birkmann, 9-54. Tokyo: United Nations University Press.

Boruff, B.J., and S.L. Cutter. 2007. The environmental vulnerability of Caribbean Island nations. Geographical Review 97(1): 24-45.

Burton, C.G. 2015. A validation of metrics for community resilience to natural nazards and disasters using the recovery from Hurricane Katrina as a case study. Annals of the Association of American Geographers 105(1): 67-86.

CBS (Central Bureau of Statistics). 2012. National population and housing census 2011. Kathmandu, Nepal: CBS.

Christensen, J.H., K.K. Kanikicharla, E. Aldrian, S.I. An, I.F.A. Cavalcanti, M. de Castro, W.J. Dong, P. Goswami, et al. 2014. Climate phenomena and their relevance for future regional climate change. In Climate Change 2013: The Physical Science Basis, working group I contribution to the fifth assessment resport of the Intergovernmental Panel on Climate Change, 1217-1308. Cambridge: Cambridge University Press.

CRED (Centre for Research on the Epidemiology of Disasters). 2015. The human cost of natural disasters: A global perspective. Brussels: CRED.

Cutter, S.L., B.J. Boruff, and W.L. Shirley. 2003. Social vulnerability to environmental hazards. Social Science Quarterly 84(2): 242-261.

Cutter, S.L., and C. Finch. 2008. Temporal and spatial changes in social vulnerability to natural hazards. Proceedings of the National Academy of Sciences of the United States of America 105(7): 2301-2306.

Cutter, S.L., and D.P. Morath. 2014. The evolution of the social vulnerability index (SoVI). In Measuring vulnerability to natural hazards: Towards disaster resilient societies, 2 nd edn., ed. J. Birkmann, 304-321. New York: United Nations University Press.

Dahal, D.R., Y.B. Gurung, B. Acharya, K. Hemchuri, and D. Swarnakar. 2002. Situation analysis of dalits in Nepal. Kathmandu, Nepal: Action-Aid Nepal, CARE Nepal, and Save the Children US.

de Haen, H., and G. Hemrich. 2007. The economics of natural disasters: Implications and challenges for food security. Agricultural Economics 37(S1): 31-45.

de Oliveira Mendes, J.M. 2009. Social vulnerability indexes as planning tools: Beyond the preparedness paradigm. Journal of Risk Research 12(1): 43-58.

Devkota, R.P., T.N. Maraseni, G. Cockfield, and L.P. Devkota. 2013. Flood vulnerability through the eyes of vulnerable people in mid-western Terai of Nepal. Journal of Earth Science \& Climatic Change 4(1): 1-7.

Dixit, A. 2003. Floods and vulnerability: Need to rethink flood management. Natural Hazards 28(1): 155-179.

Dixit, A.M. 2014. Risk and vulnerability assessment: Experience of Nepal. In Civil society organization and disaster risk reduction: The Asian dilemma, ed. R. Shaw, and T. Izumi, 79-113. Japan: Springer.

Dixit, A., M. Upadhya, A. Pokhrel, K.M. Dixit, D.R. Rai, and M. Devkota. 2007. Flood disaster impacts and responses in Nepal Tarai's marginalized basins. In Working with the winds of change: Toward strategies for responding to the risks associated with climate change and other hazards, ed. M. Moench, and A. Dixit, 119-158. Kathmandu: ProVention Consortium, Institute for Social and Environmental Transition-International, and Institute for Social and Environmental Transition-Nepal.

Dixit, A.M., R. Yatabe, R.K. Dahal, and N.P. Bhandary. 2013. Initiatives for earthquake disaster risk management in the Kathmandu Valley. Natural Hazards 69(1): 631-654.

Few, R., and G.T. Pham. 2010. Climatic hazards, health risk and response in Vietnam: Case studies on social dimensions of 
vulnerability. Global Environmental Change-Human and Policy Dimensions 20(3): 529-538.

Fuchs, S., J. Birkmann, and T. Glade. 2012. Vulnerability assessment in natural hazard and risk analysis: Current approaches and future challenges. Natural Hazards 64(3): 1969-1975.

Hewitt, K (ed.). 1997. Regions of risk: A geographical introduction to disasters. Singapore: Longman.

Holand, I.S., and P. Lujala. 2013. Replicating and adapting an index of social vulnerability to a new context: A comparison study for Norway. Professional Geographer 65(2): 312-328.

Huggel, C., A. Raissig, M. Rohrer, G. Romero, A. Diaz, and N. Salzmann. 2015. How useful and reliable are disaster databases in the context of climate and global change? A comparative case study analysis in Peru. Natural Hazards and Earth System Sciences 15(3): 475-485.

Hummell, B.M.D., S.L. Cutter, and C.T. Emrich. 2016. Social vulnerability to natural hazards in Brazil. International Journal of Disaster Risk Science 7(2): 111-122.

Immerzeel, W.W., L.P.H. van Beek, M. Konz, A.B. Shrestha, and M.F.P. Bierkens. 2012. Hydrological response to climate change in a glacierized catchment in the Himalayas. Climatic Change 110(3): 721-736.

Juran, L., and J. Trivedi. 2015. Women, gender norms, and natural disasters in Bangladesh. Geographical Review 105(4): 601-611.

K.C., S. 2013. Community vulnerability to floods and landslides in Nepal. Ecology and Society 18(1): Article 8.

Laska, S., and B.H. Morrow. 2006. Social vulnerabilities and Hurricane Katrina: An unnatural disaster in New Orleans. Marine Technology Society Journal 40(4): 16-26.

Letsie, M.M., and S.W. Grab. 2015. Assessment of social vulnerability to natural hazards in the Mountain Kingdom of Lesotho. Mountain Research and Development 35(2): 115-125.

Mainali, J., and N.G. Pricope. 2017. High-resolution spatial assessment of population vulnerability to climate change in Nepal. Applied Geography 82: 66-82.

Mallick, B., K.R. Rahaman, and J. Vogt. 2011. Social vulnerability analysis for sustainable disaster mitigation planning in coastal Bangladesh. Disaster Prevention and Management 20(3): 220-237.

Ministry of Environment of the Government of Nepal. 2010. National adaptation programme of action to climate change. Kathmandu, Nepal: Ministry of Environment, Government of Nepal.

Montz, B.E., and G.A. Tobin. 2011. Natural hazards: An evolving tradition in applied geography. Applied Geography 31(1): 1-4.
Myers, C.A., T. Slack, and J. Singelmann. 2008. Social vulnerability and migration in the wake of disaster: The case of Hurricanes Katrina and Rita. Population and Environment 29(6): 271-291.

Papathoma-Kohle, M., M. Kappes, M. Keiler, and T. Glade. 2011. Physical vulnerability assessment for alpine hazards: State of the art and future needs. Natural Hazards 58(2): 645-680.

Scott, L.M., and M.V. Janikas. 2010. Spatial statistics in ArcGIS. In Handbook of applied spatial analysis: Software tools, methods and applications, ed. M.M. Fischer, and A. Getis, 27-41. Berlin: Springer.

Sharma, P., B. Guha-Khasnobis, and D.R. Khanal. 2014. Nepal human development report 2014. Kathmandu: National Planning Commission, Government of Nepal, and United Nations Development Programme.

Shrestha, A. 2005. Vulnerability assessment of weather disasters in Syangja District, Nepal: A case study in Putalibazaar Municipality. Nepal: Department of Hydrology and Meteorology.

Shrestha, A.B., and R. Aryal. 2011. Climate change in Nepal and its impact on Himalayan glaciers. Regional Environmental Change 11(1): $65-77$.

Shrestha, A.B., C.P. Wake, P.A. Mayewski, and J.E. Dibb. 1999. Maximum temperature trends in the Himalaya and its vicinity: An analysis based on temperature records from Nepal for the period 1971-94. Journal of Climate 12(9): 2775-2786.

Sudmeier-Rieux, K., S. Jaquet, M.H. Derron, M. Jaboyedoff, and S. Devkota. 2012. A case study of coping strategies and landslides in two villages of Central-Eastern Nepal. Applied Geography 32(2): 680-690.

TU-CDES (Tribhuvan University-Central Department of Environmental Science). 2016. Landslide inventory characterization and engineering design for mitigation works of Chure area in ten districts. Kathmandu, Nepal: Central Department of Environmental Science (CDES), Tribhuvan University (TU), and President Chure-Tarai Madhesh Conservation Development Board, Government of Nepal.

UNDP (United Nations Development Programme). 2016. Human development report 2016: Human development for everyone. New York: UNDP.

Wisner, B., P. Blaikie, T. Cannon, and I. Davis. 2004. At risk: Natural hazards, people's vulnerability and disasters, 2nd edn. London: Routledge.

Zhou, Y., N. Li, W.X. Wu, J.D. Wu, and P.J. Shi. 2014. Local spatial and temporal factors influencing population and societal vulnerability to natural disasters. Risk Analysis 34(4): 614-639. 